\title{
Automated People Movers: A Futuristic Approach to Modern Transportation Planning
}

\author{
Shumank Deep Srivastava ${ }^{1}$, and Ruchin Agrawal* \\ 1Student M.Tech (CTM), AM.A.S.C.E, Assistant Professor* \\ Department of Civil Engineering, Bundelkhand Institute of Engineering \& Technology, Jhansi \\ Department of Civil Engineering, Kamla Nehru Institute of Technology, Sultanpur
}

\begin{abstract}
Automated people mover (APM) refers to fully automated, grade separated mass transit system. These systems are utilized in relatively small areas such as airport, theme parks etc. Since beginning in 1964 these systems have gone through a series of developments and transformations which resulted in the present APM. People movers use technologies such as monorail, duorail, automated guideway transit or maglev. APMs deploy fleets of small vehicles over a track network with off-line stations, and supply near non-stop service to passengers. This paper highlights the developmental transition of APMs and ATSs right from their evolution, covering all the change mechanisms involved in the process of evolution. The various needs and factors which catapulted in the technical and technological advancement of this ongoing and ever-evolving field of niche transportation have been thoroughly explored. Also a detailed critical comparison with other existing transportation systems of the same genre is drawn out.

Key words: APM, personal rapid transit, Automated Guideway transit, maglev, podcar, guideway, intrusion prevention system, automatic train protection
\end{abstract}

\section{Introduction}

India is poised for rapid economic growth propelled by the industrial and service sectors. Since economic activities in these sectors primarily take place in urban areas, the state of our towns and cities is crucial to India's future growth. Further, India's urban population is currently around $30 \%$ of its total population. Experience across the world has been that as economies grow, rapid urbanization takes this proportion to over $60 \%$ before it begins to stabilize. As such, it is projected that India's urban population would grow to about 473 million in 2021 and 820 million by 2051, as against only 285 million in 2001. Hence, cities must not only meet the mobility needs of the current population but also provide for the needs of those yet to join the urban population.

In $21^{\text {st }}$ century, modern communication technologies have brought consumers Wi-Fi, Bluetooth, and other high speed tech gadgets, the transportation community has shown its niche interest on driverless transit systems, a spectrum of automated guideways transit systems, such as automated people movers, downtown people movers, group rapid transit, and driverless metro and personal rapid transit. After more than four decades of research and development, the AGT technology is not limited to airport use as shuttles or circulators. It has expanded to downtown and metropolitan areas such as major activity centre circulation and public transit systems. Another surging presence of APM is observed in various leisure and recreation facilities and public and private institutions. Automated people movers (APMs), known as advanced public transport systems or smart transport option, are normally relatively large vehicles (30-100passengers) running on a special rail without driver, where the rail is normally structured as a simple line with online stations. APMs also as heavy rail systems may typically carry considerably large numbers of passengers. At present there are about 150 APM installations in operation around the world moving about five million passengers daily. About 30 percent of APMs are within and around airports, and the rest are mostly around dense urban centres (i.e. central business districts). About one third of them are mass public transport of one form or another- driverless metros and district circulators. The rest are in private leisure and institutional settings. These prototype projects offer promising ideas for the planning of future sustainable urban and transport development.

Automation of trains and van-like vehicles means that the urban mobility services can be frequent and economic. This is not true for buses and conventional rail, for each 'run' requires the cost of a driver, resulting in a tendency to provide as few as acceptable. APMs eliminate this tendency, resulting in reduced wait times for passengers and making the service significantly more attractive to them. A fledgling APM industry has emerged, as witnessed by a series of conferences and standards organised by committees of the American Society of Civil Engineers. Fabian recently reviewed the APM industry and provided a list of active APM companies. The International Mass Transit Association has also noticed the accomplishments and potential of driverless metros progress and focused their attention on APMs.

Some APM concepts take the implications of automation a step further. They put stations off-line so 
that a very dense flow of vehicles is possible and so that each trip can be scheduled in real time without stops at intermediary stations. This is true not just for movements down a linear corridor, but also throughout a flexibly configured network. Known as Personal Rapid Transit (PRT), the service is more like automated taxis than driverless trains. Contrary to light or heavy rail APMs, PRTs could run feasibility over 3 or 4 passengers. The service potential of PRT is significantly more attractive than most APMs - high enough that it can be expected to significantly affect the car ownership decisions and mode split patterns.

\section{TECHNOLOGY}

Automated guideway transit is defined as al class of transportation systems in which vehicles operate along a dedicated guideways. APMs range in size from very small to a few hundred metres long and with light capacities of a few thousand passengers per hour direction to full scale driverless metros with line capacities of up to 40,000 .the operating speeds are from 10-35 miles per hour (mph), and headways may vary from a few seconds to few minutes. The guideway system may be made of a single trunk route, multiple branches or interconnected networks. However, they all entail full integration of electronic communication and controls, which eliminates the need for vehicle and station attendants. Several companies form the core of APM supply industry that has project pipeline worth about $\$ 6$ billion. These projects include an increasingly sophisticated mix of system supply, fleet additions, test tracks, and vehicle and system rehabilitation and upgrading, in addition, many organizations maintain and even operate APMs for clients.

Compared with rail transit, the construction period of APMs can be remarkably fast. Small systems can be designed and installed in less than a year. This smaller scale is amenable to design-build-operate contracting. To satisfy temporary needs APMs can be supplied for a limited time, then dismantle and removed after a season of 5-10 years.

Building an APM is a major commitment of capital resources. Public and private planners therefore typically investigate less capital intensive solution to mobility needs and congestion problems, including transportation management, pedestrianization schemes and shuttle busses all capable of being enriched with advanced communication.

Civil work can amount to 50-70\% of the capital cost to self propelled vehicle systems, the bulk of expense being in fixed facilities i.e. the guideway, stations, and maintenance infrastructures. The civil cost largely depends on how APM is designed into its environment.

Realizing the benefits of standardization to organisations that specify and procure APM systems the American society of Civil Engineers (ASCE) has taken the initiative of developing "Automated People Movers Standards". These include minimum requirements for design, construction, and operation, and maintenance of APM systems especially on the cases of physical operating conditions. Though these standards are not legally authorised by any authority that has jurisdictions over AGT applications, yet they serve as general guideline for the transportation professionals for construction and management of AGT systems.

\section{MINIMUM REQUIREMENTS AS PER ASCE GUIDELINES}

Vehicles: As per article 7 of APM standards 21.22008 allowable operating speed upto $100 \mathrm{~km} / \mathrm{hr}(60 \mathrm{mph})$. Total passenger area shall be all of the area available to seated and standing passengers. Standing floor area is the total passenger area less than 0.42 sq.ft. ( 4.5 sq.ft) for each nonremoveable and non-stowable seating positions a width of $0.45 \mathrm{~m}$ should be allocated for seated passengers.

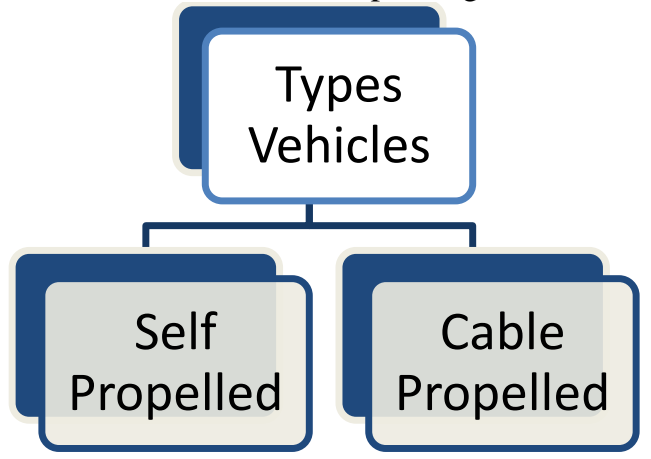

Guideway: it is one of the most vital elements of AGT applications, comprising of tracks and all other running surfaces including the support structures that contains and physically guides the vehicle to travel exclusively on the guideway. The guideway can be elevated, at-grade and underground depending on the requirement of the situation. The guideway shall be designed and constructed in such a way that the ride quality criteria and the vehicle clearance restrictions are met along the entire alignment. The guideway shall be designed to support all loads and forces associated with vehicles, vehicle interfaces, the environment, and any other facilities affixed to the guideway. The guideways should be constructed in such a way that it should provide guidance and support 
to passenger as well as service vehicles.

The individual components of an AGT guideway usually include running surfaces, guidance and running rails, power distribution rails, signal rails and communication rails and switches. For systems that use linear induction motor for propulsion guideway equipment may also include rotor (reaction rails), or a stator.

Another vital constituent of guideways is called crossovers; these provide the means for the vehicles to move between the guideways lanes. It is generally composed of two switches connected by a short length of a special track work. The guideway should be designed and constructed as per the vehicle criterion as per section 7.7.3 of the ASCE transportation and development institute guidelines. Horizontal alignment may consist of any of the combinations of straight (tangent) sections, spiral transitions, and curved sections. Besides this the effect of superelevation, ride comfort criteria, and the related limitation of operating speed shall be considered in establishing the horizontal alignment. At the stations the guideway shall be so designed so that the vehicle floor shall not be inclined by more than $1 \%$ in the direction with respect to the horizontal plane. At other stoppage locations other than stations the angle of the vehicle floor inclination shall not exceed $12 \%$ with respect to the horizontal plane.

The maximum allowable clearance between the vehicle and the station platform edge for slow speed vehicles shall not be greater than $25 \mathrm{~mm}(1.0 \mathrm{inch})$ and height of the vehicle should be within $\pm 12 \mathrm{~mm}(0.5 \mathrm{inch})$, for other fast moving vehicle the permitted clearance is $50 \mathrm{~mm}(2.0 \mathrm{inch})$ and the height of vehicle floor should be $\pm 15.5 \mathrm{~mm}(0.625$ inch $)$.

Propulsion and System Power: Inorder to propel the system and make the other operating equipment work electric power is required; these systems are configured in such a manner that system operating power will be supplied by the substations located along the guideway.

- Self-propelled system comprises of electric traction motors or linear induction, motors. The APMs are electrically powered by onboard AC or DC motors using either 750 or $1300 \mathrm{~V}$ DC or 480 or $600 \mathrm{~V} \mathrm{AC}$ wayside rail based power-distribution sub-systems. Also these systems are not limited in guideway length.

- Cable propelled these systems employ a steel cable or "rope" to pull vehicles along the guideway, an electric motor is used for driving the vehicles and is located alongside the guideway. This technique can only be employed for shorter distances upto $4000 \mathrm{ft}$. Since the operation require the usage of large amount of electricity and also the operation space is low the research is still on for improvement of this technique.

Communication and Control: AGT applications are marked with automated control and communication systems, which are very different from conventional system, for operating these driverless vehicles to command and control them. The companies manufacturing these systems have also to provide different component to house the automatic train control equipment, automatic train operation, and automatic train supervision equipment. Besides these the safety criteria enforcement is ensured by automatic train protection.

The AGT system includes a communication network monitored and supervised by the central control facility. The network typically includes a station PA system, operation and maintenance radio system, emergency telephone, and a CCTV monitor.

Stations \& Platforms: the station of APM systems are located along the guideway in a similar manner to the conventional railroad transit systems. These stations are generally equipped with automatic platform doors and dynamic platform station signs. The AGT stations typically have station room to contain command, control and communication equipment. In addition to automatic train doors, the station has doors that align with a stopped train and the two door system operates in tandem. These doors provide a barrier between the passengers and the vehicles operating on the guideway. This system also known as intrusion prevention system shall meet the following requirements:

1. Platform edge doors shall be compatible with the criteria prescribed as ASCE/T\&DI guidelines 21-05, Section 5.2.2, with height equal to or greater than that of the vehicle door opening.

2. The platform edge barriers, door assembly, supporting-tracks, and linkages shall withstand a force of $1.11 \mathrm{~N}$ applied perpendicular to and approximately at the centre of the panel, distributed over an area of $100 \mathrm{~cm}^{2}$ without permanent deformation or binding of the door mechanism.

3. If glass is used in station platform edge barriers or platform doors, the glass shall comply with the requirements of standard specification for flat glass, ASTM 1036-06.

4. Platform edge doors shall comply with ANSI/ASCE/T\&DI 21-05. Section 5.1.1 and 5.1.11, and all applicable requirements of ASCE/T\&DI 21.2-08, section 7.8 regarding, locking, closing forces, obstruction detection and emergency exit. A keyed platform side lock shall be provided to allow the authorized access to the guideway for maintenance and evacuation purpose.

5. Initiation of door closing of platform edge door shall be annunciated by audio and visual warning signals as specified in ANSI/ASCE/T\&DI 21-05 section 6.3.2. 
6. The space between the platform doors and the vehicle doors shall be designed to prevent door closure when passengers are in space between the vehicle doors and platform doors, unless the gap is less than $130 \mathrm{~mm}$ (5 in.) from the platform level up to $1.1 \mathrm{~m}$ (42 in.) above the platform level.

7. Vehicle and station platform door opening and closure

Also a intrusion control system can be provided that must include barriers with height of $1.1 \mathrm{~m}$ and automatic horizontal sliding doors and gates.

Maintenance and Storage Facilities: Another key element of AGT system is the maintenance and storage facilities, which serve as a hub for maintenance and storage and administrative functions. The maintenance includes the cleaning, washing; shipping, receiving, and storage of parts and spare equipment, fabrication of parts, and storage of spare vehicles.

The MSF typically is located away from the operating alignment in the larger AGT system, such as airport circulation system, DPMs, or DLMs. Vehicle testing and test track function are generally carried out on the guideway approaching the MSF when the facility is separate from the operating guideway. Simple, smaller shuttle systems often have MSF located under one of the system station or towards the end of the alignment. The maintenance program shall be comprehensive and shall be incorporated into all aspects of the system design. The maintenance program shall include the development of the system maintainability data for the full systems and subsystems; planning procedures for preventive maintenance; procedures for corrective maintenance and documentation of all processes and part in maintenance manuals.

\section{APMs IN ASIA REGION}

Currently APMs are operational in Hong Kong, China, Republic of Korea, Taiwan, Japan, Singapore and Malaysia at various international airports in located in the major cities of these countries. Besides these some of the APM projects planned to be developed are located at Dubai, UAE, and one PRT project at Amritsar, India.

Hong Kong International Airport APM system Hong Kong International Airport Automated People Mover is located within Hong Kong International Airport. It operates in two "segments" and depends on the direction of travel. First segment runs between the East Hall and the West Hall in Terminal 1. The segment aims to provide a faster and easier way for passengers travelling between immigration and boarding gates at the far end of the Terminal. Westbound service is for departure of passengers.

While eastbound service is only for arrival passengers. After arriving at the West Hall, departure passengers should approach the boarding gates nearby and board their plane. It is not allowed to take the APM back to the East Hall, where most shops located. For eastbound service, after reaching the East Hall, all arrival passengers must disembark for immigration, customs, and baggage claim. Also, it is not allowed for arrival passengers to take the APM back to the West Hall. Since both the East Hall and the West Hall are located within Terminal 1, passengers can choose not to use this system but use travellators or walk instead, though this will be more time-consuming.

Second segment of the system runs from Skyplaza to Terminal 2 and then continue to the East Hall of Terminal 1. Different from the first segment, the second segment is the only way connecting these three places. Skyplaza passengers heading for departing flights must take the westbound service of this segment to the East Hall of Terminal 1. SkyPlaza passengers are not allowed to alight at Terminal 2. Departure passengers from Terminal 2 can join the westbound service of the second segment from Terminal 2. All passengers must leave the train when it is arrived at the East Hall of Terminal 1. Then depends on the boarding gate location of their

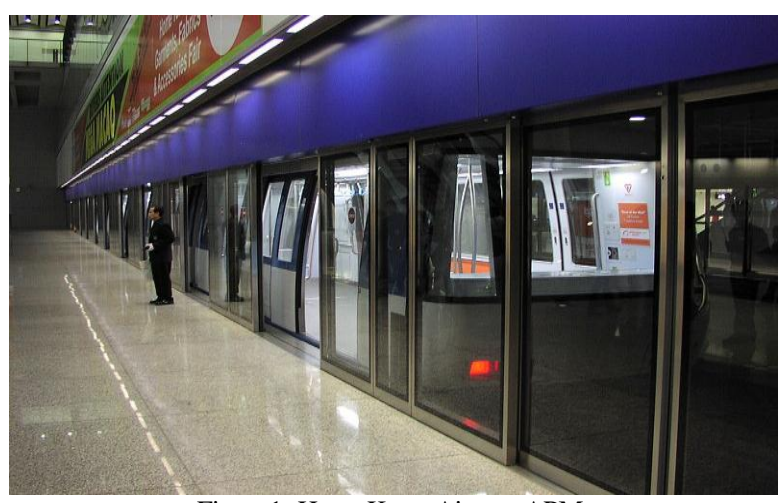

Figure1: Hong Kong Airport APM onward flight, passengers can choose to change to the first segment of APM system at the opposite platform of the East Hall to continue their way to the West Hall, or simply approach the boarding gate from the East Hall directly. The westbound service is only for arrival passengers heading to Skyplaza for ferry service to PRD ports. Ferry ticket will be checked before boarding the APM. Once arrived at Skyplaza, passengers are not allowed to travel back to the Terminal 1. Since there is no eastbound platform in Terminal 2, there will be no intermediate station for the eastbound service.

The section from the East Hall to Skyplaza is for Skyplaza passengers and staff 


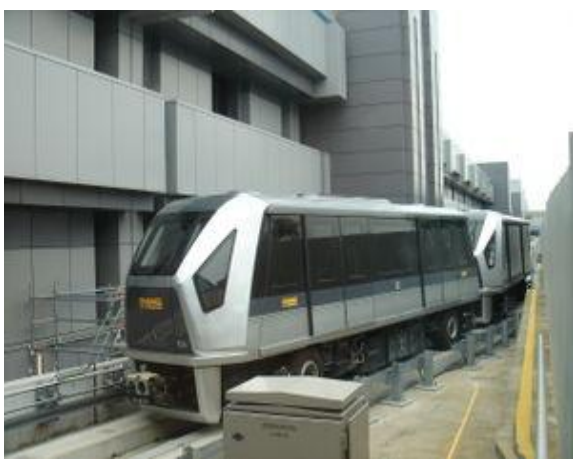

only. The first segment began operations in 1998 while the second one began operations in early 2007. SkyPlaza extension was opened to public in late 2009.

SkyPlaza APM System The construction of this system covers the reinforced concrete track (excluding the APM vehicle), steel guide rail, maintenance area, power distribution system, power rail, communication system and ATC (Automatic Train Control). The ATC comprises ATP (Automatic Train Protection) to support safe operation; ATO (Automatic Train Operation) to control automatic operation, including door opening/closing and vehicle accelerating/ decelerating; and ATS (Automatic Train Supervision) to command, monitor, and record the operation. The total APM system configuration is shown below.

Fig 2: crystal People Mover

\begin{tabular}{|l|l|}
\hline Rigid conductor power rail & Supplying power to the APM vehicle \\
\hline Reinforced concrete track & Running surface for the APM vehicle \\
\hline Guide rail and point switch & For guiding the APM vehicle \\
\hline Power distribution system & Power receiving, voltage reduction, and distribution \\
\hline Buffer & For stopping the vehicle \\
\hline ATP & Automatic train protection(APM safety device) \\
\hline ATO & Automatic train operation( operation of APM) \\
\hline Communication System & $\begin{array}{l}\text { Public address to the vehicle and platform, and intercom between passengers and the } \\
\text { operator at the airport's operation control centre }\end{array}$ \\
\hline Maintenance Area & For APM vehicle storage and maintenance \\
\hline
\end{tabular}

Table 1: From a case study of Skyplaza APM System

Every subsystem is configured to conform to the domestic APM system. In consideration of redundancy, a dual or duplex hardware configuration is adopted to secure high reliability.

Changi Airport Skytrain The Changi Airport Skytrain is a people mover system that connects Terminals 1, 2 and 3 at Singapore Changi Airport. Opened in 1990, it was the first auto-guided system in Asia. The Changi Airport Skytrain operates from 0500 to 0230 daily and operates at 1 to 2 -minute intervals. Travel on the Skytrain is free and an inter-terminal journey takes about 90 seconds. All stations have platform screen doors, are air conditioned and have plasma displays indicating the arrival time of the next train. With the opening of the Changi Airport MRT Station on 8 February 2002, the Skytrain is able to connect passengers at Terminal 1 to the MRT station entrances located at Terminals 2 and 3. Initially, the Skytrain consisted of Adtranz C-100s, jointly built by Westinghouse and Adtranz. In 2002, work began on a new S\$135 million Mitsubishi Crystal Mover-based system to accommodate the planned opening of Terminal 3 and the projected increase in demand as the airport expands.

The previous rolling stock of Adtranz C-100 ran without a second carriage per train (as opposed to the current Mitsubishi Crystal Movers, which runs with two carriages per train), and the first two platform screen doors of each station were for emergency purposes (The C-100s stopped at the outer half of each station, with two doors on each half.). The third rail, formerly at the centre of the track, was moved to the side. The new system opened in March 2006 between Terminals 1 and 2 and opened the connection with Terminal 3 in November 2007 during Terminal 3's open house.

Dubai Metro The Dubai Metro is a driverless, fully automated metro rail network in the United Arab Emirates city of Dubai. The Red Line and Green are operational, with three further lines planned. These first two lines run underground in the city centre and on elevated viaducts elsewhere (elevated railway). All trains and stations are air conditioned with platform edge doors to make this possible. The first section of the Red Line, covering 10 stations, was inaugurated on 9 September 2009, with the line opening to the public at 6 AM on 10 September. The Dubai Metro is the first urban train network in the Arabian More than 110,000 people, which is nearly 10 per cent of Dubai's population, used the Metro in its first two days of operation. The Dubai Metro carried 10 million passengers from launch on 9 September 2009 to 9 February 2010 with 11 stations operational on the Red Line. Engineering consultancy Atkins provided full multidisciplinary design and management of the civil works on Dubai Metro. Architecture firm Aedas were the architect who designed for 
Dubai system's 45 stations, two depots and operational control centres. Guinness World Records has declared Dubai Metro as the world's longest fully automated metro network spanning at 75 kilometres (47 mi).

\section{International Automated People Movers.}

Detroit People Mover (USA) is a 2.9-mile (4.7 km) automated people mover system which operates on a single set of tracks, and encircles Downtown Detroit, Michigan. The People Mover is owned and operated by the Detroit Transportation Corporation. The Woodward Avenue Light Rail line, construction will commence in 2013, will be a link between the Detroit People Mover and SEMCOG Commuter Rail with access to DDOT and SMART buses as segment of a comprehensive transportation network in Detroit. The People Mover employs UTDC ICTS Mark I technology and the cars are driverless. A siding enables the system to be used in a two-way bypass manner when part of the circular track is closed.

The Mover costs $\$ 12$ million annually in city and state subsidies to run. The cost-effectiveness of the Mover has drawn criticism. In every year between 1997 and 2006, the cost per passenger mile exceeded \$3, and was $\$ 4.26$ in 2009, compared with Detroit bus routes that operate at $\$ 0.82$ (the New York City Subway operates at $\$ 0.30$ per passenger mile). The Mackinac Center for Public Policy also claims that the system does not benefit locals, indicating that less than $30 \%$ of the riders are Detroit residents and that weekend ridership (likely out-oftowners) proves to be smaller than that of weekday usage. The system was designed to move up to 15 million riders a year. In 2008 it served approximately 2 million ridership was observed.

Indiana University Health People Mover The Indiana University Health People Mover, formerly the Clarian Health People Mover, is 1.4-mile $(2.3 \mathrm{~km})$ long people mover in the city of Indianapolis, Indiana, in the United States. The system opened on June 28, 2003, to connect the Methodist Hospital of Indianapolis, Indiana University Hospital and the James Whitcomb Riley Hospital for Children, jointly operated as a single hospital by Indiana University Health. The dual-track system is open to the public and operates around the clock, taking 5 minutes in each direction. During the daytime, a train departs automatically every six minutes. It is notable for being the only private transportation system in the United States constructed to run above public streets. In 1997, the three hospital operations were combined under Indiana law creating a shared staff of over 10,000 employees who could be required to travel between the campuses. Commuting between the three sites was complicated and required the crossing of the Interstate 65 highway by shuttle buses. In May 2000, a Health Care Transportation System Franchise Agreement was signed, followed by the People Mover State of Indiana Airspace Agreement and Lease in November 2000 to allow crossing under the Interstate 65 highway for a period of 25 years.

Jacksonville Skyway The Jacksonville Skyway is a people mover in Jacksonville, Florida, United States. An automated monorail train, it is operated by the Jacksonville Transportation Authority. Opening in 1989 with three stations in Downtown Jacksonville the Skyway has been extended in 1996, 1998, and 2000, following a conversion from Matra technology to Bombardier equipment. The system currently comprises two routes across 2.5 -mile $(4.0 \mathrm{~km})$ of track, serving eight stations and crosses the St. Johns River on the Acosta Bridge. There is currently no fare to ride the Skyway, which had 481,000 passengers in the 2011-2012 year. The Skyway runs on an elevated two-way monorail track. The 2.5 -mile $(4.0 \mathrm{~km})$ system serves eight stations in Downtown Jacksonville: five in the Downtown Core and LaVilla areas, and three across the St. Johns River on the Southbank. There are two routes running south from Rosa Parks Transit Station and branching at Central Station: one going west and terminating at Convention Center Station, and the other going south over the river and terminating at Kings Avenue Station on the Southbank. The system has used two car and control systems since its creation. From 1989 to 1996 it had a system designed by Matra using its VAL rubber-wheeled technology. This ran only on the 0.7-mile $(1.1 \mathrm{~km})$, three station Phase I-A segment. In 1997, this was replaced by the current system designed by Bombardier Transportation, a version of its UM III monorail technology. In the current system, vehicles run on beams 34 inches $(86 \mathrm{~cm})$ wide and 28 inches $(71 \mathrm{~cm})$ deep, fixed on an 11foot $(3.4 \mathrm{~m})$ wide guideway with parapet walls. Each train is automated by Automatic Train Control (ATC), can have two to six cars, and travels at up to $35 \mathrm{mph}(56 \mathrm{~km} / \mathrm{h})$ per hour.

\section{Indian Scenario}

Though the country has made a lot of progress in transportation systems i.e. introduction of metro rails and monorails, expressways and dedicated freight corridor yet a lot work is yet needed to be done for implementation of automated people movers in India. The only people mover system used in India is the "tramways" a frequent service for mass transit used in the urban centres of Kolkata, West Bengal. Tramcars stand out in comparison to other vehicular modes within the transport system of Kolkata for its uniqueness. This cheap, electrically operated pollution-free mode, having a high carrying capacity is the most viable option for crowded cities like Kolkata. Slow though it ensures a safe journey through fast moving crowd. Populated cities of the world are reviving the Tramways system since it runs on electricity and has a high carrying capacity. However the situation in Kolkata is quite different. There is a constant rise in 
passenger demand but the proportion met by tramways system has been decreasing over the years, particularly because of the strong competition it has to face with buses. Undoubtedly thus the Calcutta Tramways Company has been running at a loss for quite some time. Experts therefore are considering to, do away with tramcars from the transport system of Kolkata. But it is to be noted that replacing trams would not only be costly but also environmentally harmful. One of the prior solution or a replacement for the ageing trams is APM systems. But due to uneven distribution of population and varying volume of commuters accessing these systems, bulkier APM could be a failure in Indian conditions also traffic caused by small vehicles such as auto-rickshaw is also a major cause of the traffic problems in the subcontinent. Hence Personal Rapid Transit Systems are an important mode of transportation that can be applied and would be a right answer to the large scale growing transport requirement. Therefore one such work has been planned at Amritsar, Punjab

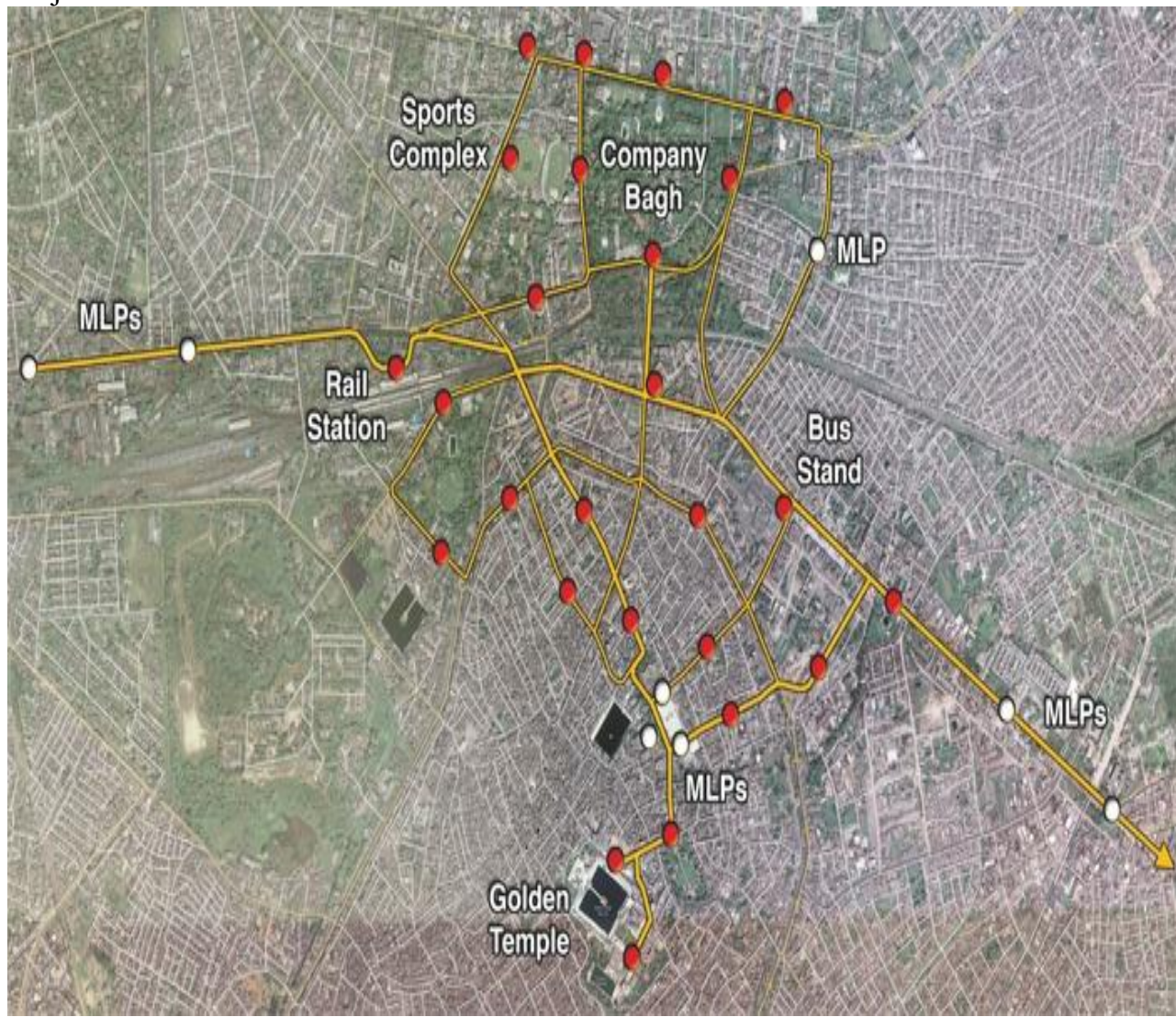

Figure 3: route map of Amritsar PRT

The project has been initiated by M/s Fairwood Green Transport, project details are

- $\quad$ Total Length 22 K.M. with 35 stations

- $\quad$ Business Model: BOT for 35 years concession.

- Initial phase of the project : 7 KM PRT Route from Rail station- Hall Bazar-Bus Stand-MLP-Golden Temple

Also one more application of this system is that it can be used as a feeder service for the Metro in metropolitan cities.

\section{Personal Rapid Transit System}

Personal rapid transit (PRT), also called podcar, is a public transportation mode comprising of small automated vehicles operating on a network of specially built guide ways. PRT is a type of automated guideway transit (AGT), a class of system which also includes larger vehicles all the way to small subway systems. In PRT, vehicles are designed for individual or small group travel, typically carrying no more than 3 to 6 passengers per vehicle. Guide ways are arranged in a network topology, with all stations located on sidings, and with frequent merge/diverge points. This approach allows for nonstop, point-to-point travel, bypassing all intermediate stations. The point-to-point service has been compared to a taxi or a horizontal lift (elevator). PRT has the following features that differentiate it from APMs and other forms of traditional transit:

- $\quad$ 24-hour on demand service

- Non-stop direct service

- $\quad$ Fully automated vehicles 


\section{- Small vehicles: one (1) to six (6) passengers \\ - $\quad$ Small dedicated guideway \\ System Components \\ Guideway}

A primary system component is the dedicated guideway which can be at-grade, elevated or underground. The guideway is structured as a network, unlike the line haul system of traditional transit. The network configuration allows vehicles to select the most direct route between stations.

PRT guideways are smaller than traditional transit requiring less right-of-way and capital expenditure and reducing visual impacts. PRT guideways are generally classified as one of the following:

- Open guideway: The system consists of a flat surface that supports the vehicle. Vehicles typically have rubber wheels and steer themselves, sensing their position relative to side walls or other fixed objects.

- Captive bogey: In this system, the vehicle is supported by the chassis it rides on. The vehicles typically have horizontal wheels that run along and are held captive by side elements. The guideway steers the vehicle.

- Suspended: Vehicles in this system are suspended (hang) from the guideway.

\section{Vehicle}

The vehicle design is dependent on guideway type and will vary by vendor. The optimum vehicle size is in the range of two to six passengers to provide convenient, demand-based service with maximized energy efficiency.

\section{Propulsion}

The PRT industry has primarily worked with electric propulsion, although some have a gas powered option. Within electric propulsion there are two concepts to consider - power source and propulsion method. Power source can be provided by batteries within vehicles or a lineside conductor (power rail). The propulsion method is typically provided by traditional rotary motors that drive wheels or linear electric motors that propel the vehicle via electromagnetic resistance.

\section{Switching}

There are two general types of switching used in transportation systems- mechanical and electromagnetic. Mechanical systems require a moving physical component, while electromagnetic methods simply guide the vehicle via magnetic attraction and no moving parts. Mechanical switching is typically a vehicle-mounted mechanism that deploys well in advance of the diverging point on the guideway and maintains control specific to each vehicle. In the event that a vehicle-mounted mechanical switch fails the problem is isolated to the vehicle. The use of electromagnetic switching is becoming more popular as the PRT technology has matured. Some systems place the switch in the guideway but like mechanical switches, a vehicle mounted switch is preferable to avoid a system wide shutdown in the event of a switch failure.

\section{Stations}

A primary feature of PRT stations is that they are situated on off-line side tracks so that through-traffic can bypass vehicles picking up or dropping off passengers. This allows the system to provide direct, non-stop service to each vehicle. Unlike traditional heavy and light rail stations that need to accommodate the full length of the train, PRT stations are sized to meet the local demand at peak times.

\section{Maintenance and Storage Facilities}

A depot is needed to service vehicles to maintain reliability, clean vehicles, and store vehicles not used during off-peak periods. Depending on the overall configuration of the PRT system the number and dispersion of depots will vary. In general it seems practical to locate depots at the periphery of urban areas where the necessary land acquisitions is more feasible or place them in areas of high demand such as near a collegiate sporting arena.

\section{System Characteristics \\ Headway}

Headway refers to the spacing between vehicles and can be defined in terms of time or distance. From a safety standpoint headways are usually determined by the stopping distance required to prevent a lead vehicle that is stopped from being struck by the vehicle behind it. The spacing of pods on the guide-way influences the overall maximum passenger capacity of the entire network, so designers prefer to achieve smaller headway distances. Testing has shown that headways of one to two seconds are achievable.

\section{Travel Speed}

PRT systems have been simulated to operate with a speed in the range of 25 to $45 \mathrm{MPH}$, which often results in an average speed of 20 to $25 \mathrm{MPH}$. These simulations factor in the impacts of system congestion on switches and potential reduced speeds under times of heavy system loads. In comparison buses average 12 
MPH and light rail averages $15 \mathrm{MPH}$.

Capacity

Capacity of PRT systems can be altered by increasing the number of vehicles or pods in the system and reducing the headways between vehicles. Studies have estimated that the capacity of a PRT system can range from a capacity similar to the auto (1,800 passengers per hour) to a capacity comparable to light or commuter rail $(14,400$ passengers per hour).

\section{Comparison of Airport Automated People movers (APM) with Personal Rapid Transit Systems (PRT) Infrastructure}

This section compares PRT and AAPM infrastructure in terms of the requirements for elevated and at-grade structures, tunnels and stations.

\section{Guideways}

The small size of PRT vehicles results in small-scale infrastructure being required. However, it can also result in limited capacity. Low-speed (less than 25 m.p.h. $(40 \mathrm{~km} / \mathrm{h}$ )) PRT systems can safely operate at headways as low as 2 seconds (PRT Consulting, Inc). While it is possible that lower headways will prove safe for PRT systems, this figure is used in this paper. Four-seat T- Pods at 2 second headways offer a maximum theoretical capacity of 7,200 passengers per hour per direction (pphpd). This compares to the maximum theoretical capacity of a typical AAPM with trains consisting of four 100-passenger cars and operating at 90 second headways of 16,000 pphpd. Thus one AAPM guideway could have more than twice the capacity of one PRT guideway. This suggests that, for guideway costs to be comparable, PRT guideways should cost about one half of AAPM guideways. However, this is not always the case as can be demonstrated by considering systems where the desired theoretical capacity is 7,000 pphpd or 20,000 pphpd. In the former case the PRT guideway could have the same costs as the AAPM guideway; in the latter case the PRT guideway should cost two thirds the cost of the AAPM guideway to be comparable.

Another complicating issue when comparing guideway costs is that AAPM systems are usually laid out as two-directional guideways serving a corridor. PRT systems can be laid out in this manner too but can sometimes be more beneficial as one-way guideways which can serve a wider area but then may require additional inter- connecting loops resulting in more total guideway length. To overcome this type of difficulty in comparing dissimilar systems, it is sometimes desirable to compare total system costs on a per-station basis.

\section{Elevated}

PRT elevated guideways need to carry a live load of less than 10 tons per span while AAPM elevated guideway spans need to support about four times this weight. PRT column loads are approximately 10 to $12 \%$ of typical AAPM column loads (Kerr, 2005). Kerr states that an elevated PRT structure has a significantly lower loading than a footbridge which must accept crowding loads.

\section{At Grade}

The at-grade requirements for an open-guideway PRT system are not much more than that for a pedestrian sidewalk. Typically the guideway can consist of a seven foot $(2.1 \mathrm{~m})$ wide pavement with eighteen inch $(450 \mathrm{~mm})$ high sidewalls, all consisting of six inch $(150 \mathrm{~mm})$ thick concrete and typically placed on about six inches $(150 \mathrm{~mm})$ of gravel base. Where AAPMs run at grade they are typically supported by two, two foot by two foot $(600 \mathrm{~mm} \times 600 \mathrm{~mm})$ concrete tracks on a supporting foundation varying in dimension according to the support capabilities of the subgrade soils. Comparing just the amount of concrete described above, the PRT guideway requires about $62 \%$ of the AAPM guideway.

\section{Below Grade}

Two PRT guideways will fit into a tunnel of half the crosssectional area required for one AAPM guideway (Muller, 2005). Comparing PRT capacity to road capacity, a 200 square foot $\left(19 \mathrm{~m}^{2}\right)$ PRT tunnel could exceed the passenger-carrying capacity of a 950 square foot $\left(90 \mathrm{~m}^{2}\right)$ vehicular tunnel (Lowson 2005).

\section{Stations}

AAPM station lengths are typically governed by the maximum train length while the width is designed to accommodate the

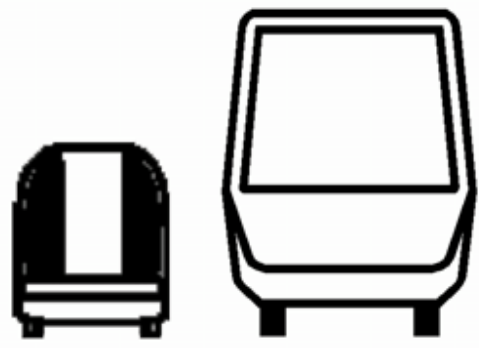

Fig 4: PRT/AAPM

vehicle size comparison AAPM tracks plus all of the people boarding and deboarding. This results in a fairly wide platform since there could theoretically be a trainload of people boarding and another deboarding at one time at 
one station. Typically the design peak number is somewhat less than this theoretical maximum number but nonetheless can be quite large. The AAPM station at Denver International Airport (DIA) Concourse B is 177 feet long by 32 feet wide (excluding the tracks) and has an area of 5,667 square feet $\left(527 \mathrm{~m}^{2}\right)$. It has an estimated capacity of about 4,000 passengers per hour.

Using a 30 second dwell time, one PRT station bay can serve about 120 T-Pods per hour. If the average TPod occupancy is 2.0 (some ride sharing is likely during peak periods in an airport), this means each station bay can accommodate 240 passengers per hour per direction for a total of 480 passengers. Thus 9 bays would be needed to match the AAPM number for DIA concourse B. A 9-bay PRT station has an area of about 4,340 square feet $\left(403 \mathrm{~m}^{2}\right)$ (excluding the tracks except at each vehicle bay) which is $76 \%$ of the area of the AAPM station. In practice, it may make more sense for a PRT system to have more stations with fewer bays, thus reducing walking distances. Such an arrangement will usually increase the relative PRT station area.

One of the major differences between AAPM and PRT stations results from the flexibility of the smaller PRT systems. Their ability to accommodate tight radii and steep gradients makes it possible for PRT stations to be accommodated within concourses and potentially at or close to grade. This offers the potential of easier use resulting in higher patronage. It also could result in the elimination, or reduction in number, of escalators and elevators. Figure 5. depicts a station designed to fit within Concourse B at DIA. It has a footprint smaller than that of the existing moving sidewalks.

\section{Capital Costs}

The only known source of modern PRT capital costs based on a construction contract is the ULTra project at Heathrow International Airport. The capital cost including guideways, stations, vehicles and operating system but excluding column footings is reported to be less than US $\$ 10$ million per one-way mile. This cost is for a system that is not expected to have a high demand and is thus probably on the low end. This type of openguideway PRT system can be expected to cost between US\$10 and US\$15 million per one-way mile. Kerr (2005) provides AAPM capital costs of US $\$ 24$ to 75 million per one-way mile. This is approximately 2.4 to 5 times the PRT costs quoted above and indicates that PRT systems will usually cost less than AAPM systems for the same capacity. This seems to confirm the results reported by Muller (2005) in a study comparing actual AAPM capital costs at Denver International Airport with estimates provided by three different PRT vendors. This study found the PRT capital cost to be $35 \%$ of the AAPM capital costs.

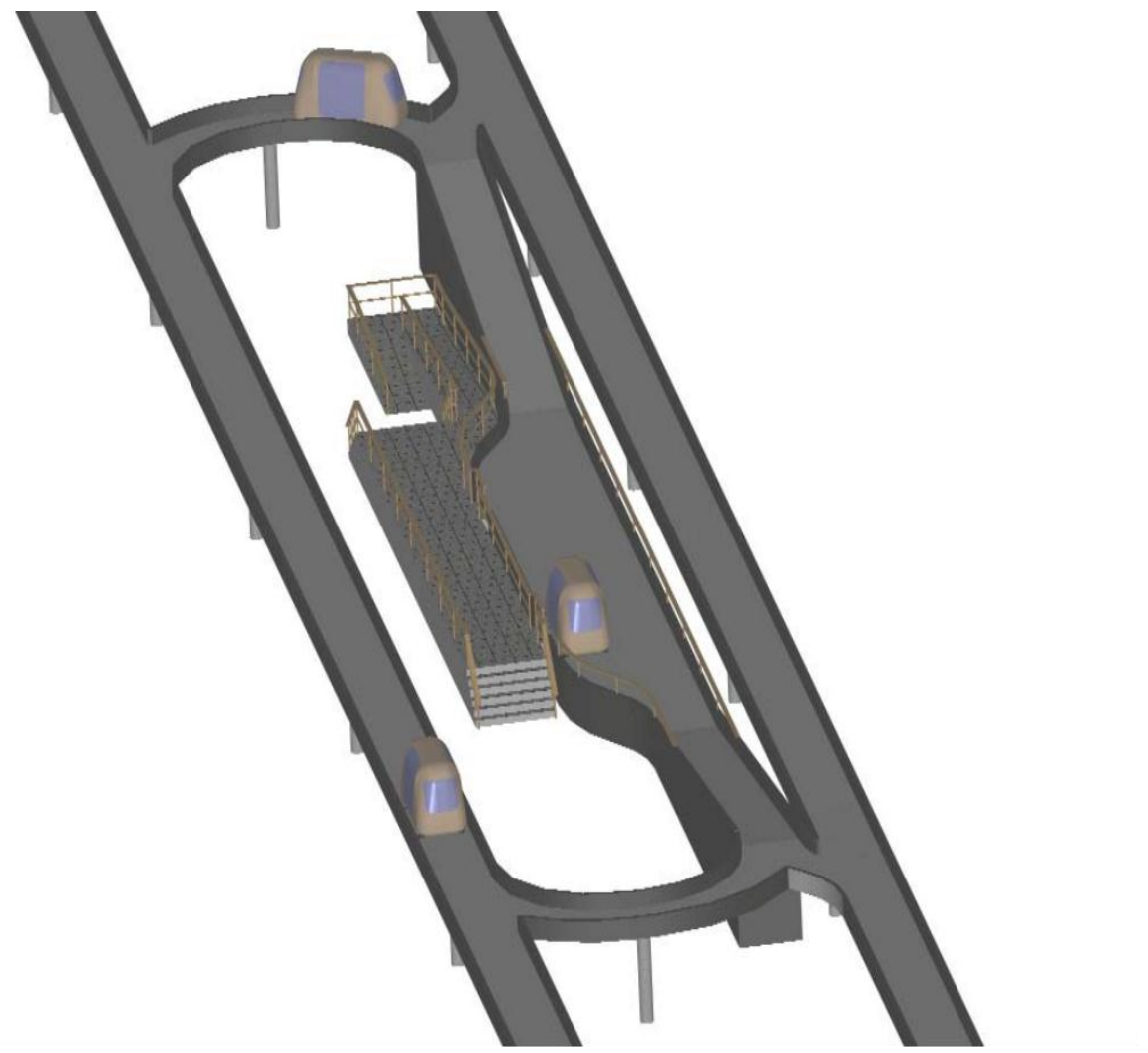

Figure 5: PRT station in operation 


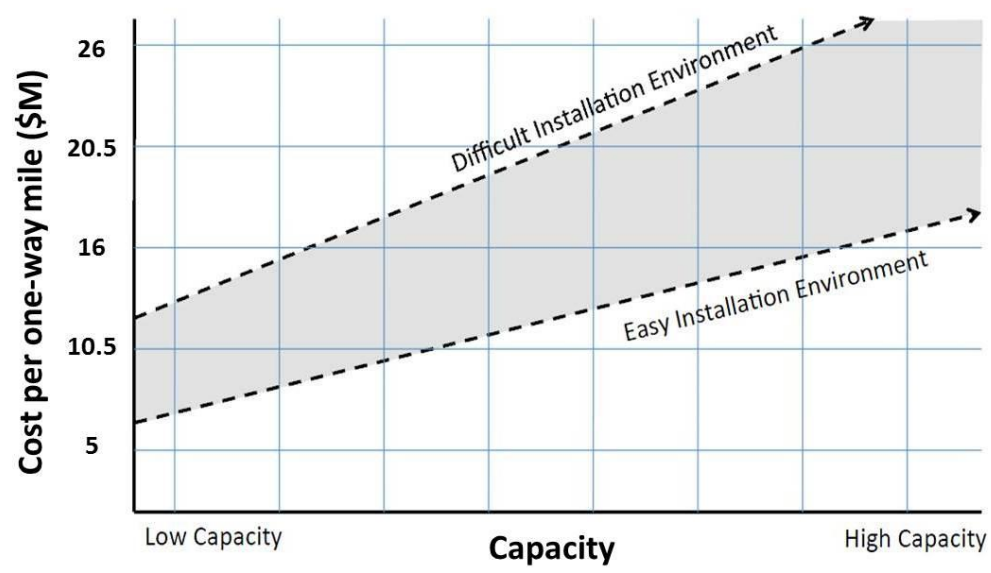

Figure 6: Capital Costs for PRT system

\section{Operating Costs}

AAPMs are typically installed in high capacity situations and therefore have relatively low (less than $\$ 1.00$ ) operating costs per passenger. Modern PRT systems are expected to have even lower operating costs but this has not yet been proven. The Morgantown PRT system has operating costs of about $\$ 1.50$ per passenger.

\section{Level of Service}

PRT level of service is designed to better match that of an automobile in uncongested conditions than that of any conventional form of transit including AAPMs. Service is on-demand with little or no waiting. Passengers are taken directly to their destinations with no stopping and in seated comfort. Way finding is simplified because the only knowledge needed is the ultimate destination, the system will find the best route. Passengers are transported in privacy with little or no need to share rides with strangers. There is little or no need for the trip to be punctuated by a public address system.

While PRT travel speeds are likely to be relatively slow initially $(25$ m.p.h. or $40 \mathrm{~km} / \mathrm{h}$.), the total trip times are likely to be less than AAPM trip times because of the reduced waiting times and the elimination of intermediate stops. Muller (2005) found PRT trip times to be $45 \%$ of AAPM trip times. In addition, PRT systems are likely to have more stations resulting in reduced walking distances and times.

\section{Safety and Security}

PRT systems are expected to be significantly safer than conventional transit systems and to match the safety record of AAPMs. The Morgantown PRT system has completed over 110 million injury-free passenger miles (Muller, 2007) providing evidence of the safety of PRT operating concepts.

Small vehicles providing on-demand service at small stations result in a lack of crowding, which in turn means that PRT systems do not present likely terrorist targets. In addition, PRT systems deliver a steady stream of traffic which could facilitate security screening. Future PRT systems could be equipped with on-board

\section{Conclusion}

From the above study, it can be concluded that Automated people movers can be considered to an alternative solution to the modern transportation need of developing countries like India and amongst its types Personal Rapid Transit Systems are easily adaptable to Indian conditions and could be a solution to the traffic problems that are being commonly faced in the urban centers and metropolitan cities. These can also be employed to serve as feeder service to metro rail stations, and major railway stations in vicinity which large volume of traffic congestion occurs due to auto-rickshaw. And all of above this system is an eco-friendly operation thereby contributing to the sustainable development.

\section{References:}

[2]. Chapter 18, handbook of transportation engineering, by Myer Kutz, volume 2

[3]. Feasibility of personal rapid transit in Ithaca, New York, by NYSERDA

[4]. A Personal Rapid Transit/Airport Automated People Mover Comparison by Peter J. Muller, P.E.

[5]. Detailed Project Report of Amritsar PRT project

[6]. Tramways an eco - friendly mode of mass transportation: a case of Kolkata by Eshita Boral 